\title{
Erratum to: Fuzzy soft rings and fuzzy soft ideals
}

\author{
Ebubekir İnan · Mehmet Ali Öztürk
}

Published online: 24 February 2013

(C) Springer-Verlag London 2013

\section{Erratum to: Neural Comput \& Applic (2012) 21 (Suppl 1):S1-S8 \\ DOI 10.1007/s00521-011-0550-5}

The authors would like to correct errors in the original publication of the article. The corrections are given below:

In page 4 , in part (2) of Theorem 6., " $\wedge_{i \in I}\left(H_{i}, B_{i}\right)$ is a fuzzy soft subring of $(F, A)$ " should be changed to " $\wedge_{i \in I}\left(H_{i}, B_{i}\right)$ is a fuzzy soft subring of $\wedge_{i \in I}(F, A)$."

In page 4, in part (3) of Theorem 6., "If $B_{i} \cap B_{j}=\varnothing$, for all $i, j \in I$, then $\vee_{i \in I}\left(H_{i}, B_{i}\right)$ is a fuzzy soft subring of $(F$, $A$ )" should be changed to "If $B_{i} \cap B_{j}=\varnothing$, for all $i, j \in I$, then $\vee_{i \in I}\left(H_{i}, B_{i}\right)$ is a fuzzy soft subring of $\vee_{i \in I}(F, A)$."

In page 5 , in section 4 "For any $t, r \in[0,1], M(t, r)$ will denote $\min (t, r) . \overline{\in \vee q}$ means $\in \vee q$ does not hold." must be omitted.

In page 5, proof of Theorem 11. (2) "is similar to (i)" should be changed to "It is similar to proof of Theorem 10."
In page 6, in part (2) of Theorem 17., " $\wedge_{i \in I}\left(H_{\mu i}, B_{i}\right)$ is a $(\in, \in \vee q)$-fuzzy soft subring of $(F, A)$ " should be changed to " $\wedge_{i \in I}\left(H_{\mu i}, B_{i}\right)$ is a $(\in, \in \vee q)$-fuzzy soft subring of $\wedge_{i \in I}(F, A)$."

In page 6, in part (3) of Theorem 17., "If $B_{i} \cap B_{j}=\varnothing$, for all $i, j \in I$, then $\vee_{i \in I}\left(H_{\mu i}, B_{i}\right)$ is a $(\in, \in \vee q)$-fuzzy soft subring of $(F, A)$ " should be changed to "If $B_{i} \cap B_{j}=\varnothing$, for all $i, j \in I$, then $\vee_{i \in I}\left(H_{\mu i}, B_{i}\right)$ is a $(\in, \in \vee q)$-fuzzy soft subring of $\vee_{i \in I}(F, A)$."

In page 7, proof of Theorem 22. (2) "is similar to (i)" should be changed to "It is similar to proof of Theorem 20."

We apologize to the readers for any inconvenience these errors might have caused.

The online version of the original article can be found under doi:10.1007/s00521-011-0550-5.

E. İnan $(\bowtie) \cdot$ M. A. Öztürk

Department of Mathematics, Faculty of Arts and Sciences, Adiyaman University, Adiyaman, Turkey

e-mail: einan@adiyaman.edu.tr

M. A. Öztürk

e-mail: maozturk@adiyaman.edu.tr 